\title{
The Pharmaceutical Industry in Russia: Reality and Prospects
}

\author{
A.I. Gordeev, Fund «Open Economics»
}

This section "Forum" is about the pharmaceutical industry in Russia. We were encouraged to debate this topic after the unveiling of the Strategy of Development of the Pharmaceutical Industry in the Russian Federation developed by the Ministry of Industry and Trade of the Russian Federation. The majority of our experts, who are authorities in the federal government, business, academia, and industrial science, believe that Russia needs a fully developed pharmaceutical industry. What are the main arguments for an intensive development of a Russian pharmaceutical industry? In our opinion, there are four major reasons.

\section{NATIONAL SECURITY}

According to the majority of our experts, the provision of national security is one of the most important arguments underpinning the necessity to develop a domestic pharmaceutical industry. Most importantly, it will serve to provide the country with pharmaceutical drugs in case of an emergency. It is, indeed, a very important point; we need to remember, however, that our pharmaceutical industry can provide simple drugs for our people no matter the situation. According to statistical data and inquiries of leading clinics, provided by STRF.ru, the share of Russian-made drugs on the market is about $70 \%$; we need to mention, however, that Russian companies have a tendency to use foreign-made raw materials instead of domestic ones.

It is true that we produce hardly any cutting-edge or very innovative drugs, but that is not a crucial factor of national security in case of a natural or military disaster. However, national security has not only a military and political dimention, but also an economi- cal one. Import-substitution, especially when there is instability in foreign currency markets, is an obvious priority of the state's social policy, because it is directly related to basic constitutional values.

\section{TECHNOLOGICAL DEVELOPMENT AND THE ECONOMY}

The pharmaceutical industry is believed to be one of the most high-techintensive industries. That means that we need at least to put serious attention on its development, as part of the implementation of the state's effort to re-calibrate the Russian economy towards more high-tech industries. The economical parameters of the Russian pharmaceutical market, such as its capacity, dynamics, stability of demand, could be a good reason for the state to focus more attention. It is remarkable that the number of people employed in the industry is not very high (50-70 thousands). The strength of any hi-tech industry is in the stimulation of scientific research, as a result of a competitive development. The innovation that drives progress in pharmacy are the achievements in biological and medical sciences. Progress in the pharmaceutical industry helps develop chemistry, physics, mathematics etc., and that will stimulate demand for the universities to train more highly qualified specialists. It is clear that a strong pharmaceutical industry drives the demand for results from the academic and industrial $R \& D$ research sector, as well as it stimulates growth in economic employment.

Pharmaceutical companies receive orders from the medicine brach to produce certain drugs, acquire information on new research and investigations, and, on the other hand, these companies can stimulate such investigations and propose new ideas to scientists. So, these companies influence both fundamental and applied research. In the entire cycle of innovation, from $R \& D$ to mass production, there is demand for very educated, highly trained people.

\section{IMPROVING PEOPLE'S QUALITY OF LIFE}

At the level of the state, the pharmaceutical industry is a mediator between the state and people with a couple of important social functions required to lengthen and improve the quality of life of the Russian population. It is obvious that we cannot realise those functions if we lack the technologies and the creative energy that would push us to do more and more research! Without the development and use of technologies, without possession of a certain amount of them, without the infrastructure for permanent innovation in this area, it is impossible to achieve a serious improvement in the quality of our health care sector. Even 


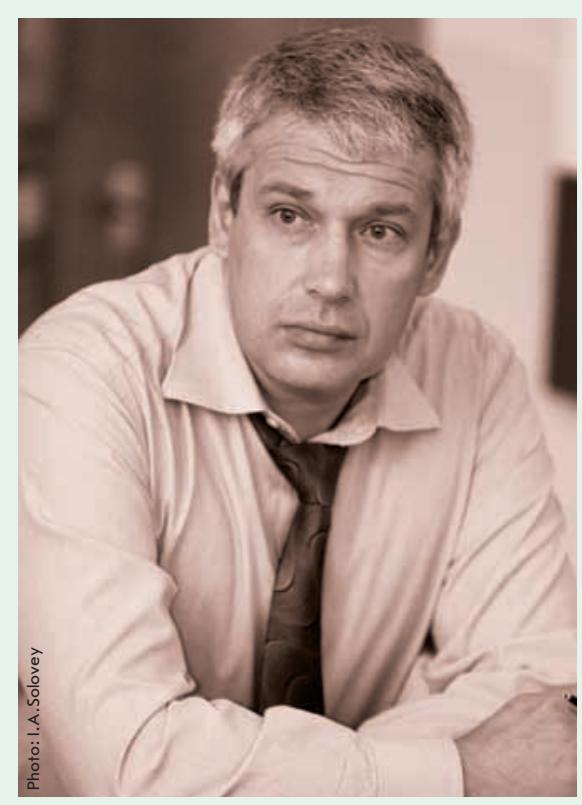

A.I. Gordeev

when we have new knowledge, new research in Russia, the pervasive nature of foreign innovations hobbles the development of an infrastructure for the production of new drugs and the development of new treatment methods. The absence of a mediator---a fully developed pharmacal industry--will result in low-quality of medical services and lack of demand for certain areas of science. There is no doubt that we can copy and use foreign research; however, we have no legal access to the best of it, and what we can buy is usually outdated and not the best. In other words, if we stop buying imported products, we will have second-tier medicine in Russia.

\section{ACCESS TO THE INTERNATIONAL PHARMACEUTICAL AND BIOTECHNOLOGY MARKET}

During the last several years Russia has lost practically all its positions on the international market of pharmaceuticals and biotechnology. A return into this market could be an important step in the effort to move from a "row material economy" to the fundamentally different participation in international trade.

\section{KEY PROBLEMS FOR DISCUSSION:}

What exactly is the Strategy "Pharma-2020"? In short, we believe it is an industry strategy with the purpose of supporting Russian pharmaceutical companies (by "Russian pharmaceutical companies" we mean any enterprise that provides a full cycle of drug production on the Russian territory). "Pharma-2020" was created with full account of the prospects of a growing domestic pharmacology market, and with the assumption that the state will invest resources into its development. Those behind the Strategy claimed that their primary goal was to create conditions for a "transition to an innovation-based model of development" of the Russian pharmaceutical industry. Yet they only schematically indicated both the mechanisms and instruments that were to ensure this transition. This is not surprising, because this was a strategy of industrial development in conditions where it is practically impossible to ensure coordination between the bureaucracies of different departments. Practically, the Strategy left untouched "border" questions, such as the provision of medical services to the people, other programs for the development of science and technology, as well as the new legislative rules that will appear as a result of collaboration between science, business, and manufacture. What are the key points we should focus on and which are crucial to potential success in the implementation of the Strategy?

\section{LACK OF A CLEAR, FUNCTINONING MECHANISM UNDERPINNING INVESTMENT IN INNOVATION}

Innovation (we plan to focus a lot of attention on innovation in this issue) is key in the creation of a full-fledged pharmaceutical industry. Do we have money for this? The world pharmaceutical industry is $2 \mathrm{nd}$ in the level of investment in research and development. This was mentioned in the analytic review «R\&D Scoreboard 2006» of the Ministry of Trade and Industry of the United Kingdom, based on an analysis of 800 British and 1,250 companies worldwide that are the most advanced in terms of investment in R\&D. Pharmaceutical companies are sandwitched between producers of high-tech gears (1st place) and car producers (3rd place); software companies come in only 5 th.

\section{LACK OF A HIGHLY ELABORATED REGULATORY SYSTEM THAT SHOULD STIMULATE THE DEVELOPMENT OF THE INDUSTRY}

We do not consider here the rules and regulations for registration, market entry, and the marketing of pharmacal companies, because they are issues that refer to the relationship between the Ministry of Industry and Trade and the Ministry of Health and Social Development. We want to focus on the problems of regulation of early steps in the innovation chain in pharmacy. If we consider the situation "in general," it would appear that there are no problems. There is a significant increase in funding for academic science, and the development of specialized industrial and state-controlled special-purpose programmes (2 programmes of the biological branch of the RAS, the Federal Special-Purpose Program of Rosnauka); there is also a new chapter in the Russian Fund of Fundamental Research; there are new state corporations and venture capital funds with state participation and the Russian Venture Company; there are the programmes "Start," "Temp," and "Pusk" at the Bortnik's Fund; and there are some changes in the regulation of Intellectual Property. However, the situation evolves very slowly, especially in pharmacology. The state is not ready to pass on the results of statefunded $R \& D$ to business; it is not ready to support high-tech industrial business without dictating the rules at all stages. The state is trapped in its own logic of administrative reform; state management has become a set of competing programmes with an unbelievable amount of criteria and regulations. That leads to lack of agreement between different departments during the implementation of the policy; and, even more confusing, the legal documents for this policy are very uncertain and contradictory. If we fail to solve the problem now, all of our steps further down the road and innovation programmes in pharmacy-industry will be ineffective. Collaboration between the Ministry of Health and Social Development and other departments and players on the pharmaceutical market is still deficient. Even if we have some reasonable ideas on how to solve this problem, we lack the mechanisms and instruments needed for implementation. Innovative 
development of the pharmaceutical industry should be based on a full innovation chain - from R\&D to the distribution of ready drugs. That means that this strategy cannot be fully elaborated without a detailed elaboration of the mechanisms of collaboration between the Ministry of Health and Social Development and other departments and state institutions. Recently, very active and effective consultations between 2 key players in the development of a domestic pharmaceutical industry - the Ministry of Industry and Trade and Ministry of and Health and Social Development - were launched. The Ministry of Industry and Trade is responsible for pharmacy as an industry; and the Ministry of Health and Social Development is a key player on the pharmaceutical market, and, particularly, a) it regulates legal aspects for the majority of parameters underpinning the process of production and marketing of drugs; b) it has departmental industrial organisations which are players on this market; c) and it is one of the major buyers on the pharmaceutical market. For a long time, the policy of the Ministry of Health and Social Development had not been helpful in the development of the Russian pharmaceutical industry. Even if the ministry sometimes proposed reasonable plans, not all of them were realised. Our bureaucrats have a fantastic ability to kill the solution to any problem and leave the situation as is convenient to them. In a modern competitive world, this approach does not work. After the replacement of the management of the Ministry of Health and Social Development, the policy of the department began to change, and some reasonable actions to improve the domestic pharmaceutical market were proposed. We have reason to believe that the realization of those proposals will solve this problem.

\section{ABSENCE OF NATIONAL PRIORITIES IN THE DEVELOPMENT OF MEDICINE AND PHARMACY}

This is one of the key problems, without the solution of which development will enter a "blind alley." Investment is considerable, and technological cycles are long in the pharmaceutical industry, and company excutives want assurences that the new drugs they develop after much investment and effort will be on demand. Development of a set of priorities, in other words selection of the main areas of medicine in need of innovative drugs is therefore a very important step; without this step, a stable development of the pharmaceutical industry is almost impossible. Are those priorities fighting cancer, cardiovascular diseases, infections or something else? This question needs an answer now, with full account of the Russian reality and the opinion of scientists and clinicians. The set of priorities is not just a list of the most important diseases. It is also important, especially for high-tech bio pharmacy, to establish priorities in the area of development of multi-functional methods and universal platforms for new molecular substances and drugs designs, such as recombinant proteins or new methods of targeted drug delivery. Because of Additional Drug Provision and the system of state procurement, the Ministry of Health and Social Development has become one of the major buyers on the market. This department influences much of what goes on on this market; nothing

\section{REFERENCE}

"Pharma-2020" (The strategy of Development of the Pharmaceutical Industry in the Russian Federation Up to 2020) was developed and proposed by the Ministry of Industry and Trade in 2008. The aim of the strategy is to develop ways towards the realisation of the priorities set in the development of the Russian pharmaceutical industry, to be the basis for a public-private partnership in the different aspects of development of the pharmaceutical industry, to provide coordination between state institutions in the development of this industry, to define vectors of development and fine-tune legislative rules regulating pharmacy and to be the basic strategy for major state decisions regarding the development and implementation of special-purpose programmes and projects. will change in Russian pharmacy without a well-thought policy by the Ministry of Health and Social Development as a major player and buyer. In this edition, we plan to look into all of the above-mentioned problems in details, and to offer a chance to the experts involved in modern drugs, technologies, and enterprises in biotechnology and pharmacy to voice their opinions.

\section{UPDATE OF THE SITUATION IN THE PHARMACEUTICAL INDUSTRY: DO WE HAVE INNOVATIVE \\ DEVELOPMENTS?}

Some experts claim that we never had a fully developed pharmaceutical industry and related scientific research. They often offer for argument the fact that we produced generic drugs, and that we borrowed most of the technology from abroad and simply focuseed on manufacturing. Moreover, they claim that all of that manufacturing went on in the republics we lost after the collapse of the Soviet Union, or in the Warsaw Pact countries. In reality, that is not true. Firstly, we still have a lot of factories in Russia. Yes, they are weak now, but we can use them to develop a future manufacturing base. Secondly, such claims have more to do with the "chemical" aspect of pharmacy; i.e. organic synthesis. In biotechnology, as experts believe, we were more advanced. A lot of our research in this area was really competitive as compared with foreign research. One of the explanations for this state of affairs is the fact that this sphere of science is related to the State MilitaryIndustrial Complex and the design of biological weapons and means for protection against them. We still have good teams, schools, and experienced people in biotechnology. Therefore, it is possible to develop bio-pharmacology in our country. In fact, the "chemical" and biotechnological bases of pharmacy are not contradictive, but complementary. They are, in fact, two ways towards the possible development of a Russian pharmaceutical industry.

In any case, we can definitely say that

a) a domestic high-tech pharmaceutical industry still exists in Russia

b) all of the innovations in this area are based on Russian scientists' R\&D (even business and science hardly criticize each other). 
Here, we will mention few examples of those R\&D:

1) The group of companies "Bioprocess," in collaboration with "Gos NIIGenetika," is designing important bio generics as a part of an innovative project (the state is co-funding this project to the tune of about 1 billion rubles). As a part of this project, they are developing an interferon alpha- $2 \mathrm{~b}$ of world-class quality with the expectation to bring it to market. This substance is needed for the treatment of Iinfluenza, upper respiratory tract viral infections, viral hepatitis $\mathrm{B}$ and $\mathrm{C}$, and some onco-diseases. They are also developing a substance of erythropoietin and some enzymes.

2) "Pharmstandart" PLC is actively marketing certain drugs that were developed at the MM Shemiakin and YA Ovchinnikov Institute of Bioorganic Chemistry of RAS; for example, "rastan" (the first domestic growth hormone), neipomax or philgrastim (it is a granulocyte colony-stimulating filter)

3) The company "Biocad" is developing its own research center. The main campus is in Liubuchany, Moscow Region, it is based on one of the state research institutes, and another campus is in Novosibirsk and is based on the Research Institute of Genetics and Molecular Biology. It is obvious that "Biocad" uses educated people who received good training from the state. But the private company, in fact, has saved the research institute and created a new system of management. Is is a real example of effective continuity; it appeared "despite," not "thanks to" the conjecture.
At almost every pharmaceutical company we were told that Russian scientists are regularly called upon to do some research. Our best intellectual resources in biotechnology and organic chemistry are concentrated in research institutes of the Russian Academy of Sciences. However, collaboration between research institutes and pharmaceutical companies seldom leads to any success. When the first private pharmaceutical companies appeared in Russia, they tried to contact all the reasonable research teams and to identify interesting projects. The result was close to nothing, because they looked for "almost ready to market" products at the stage of marketing or, at the very least, at the stage of clinical trials. Russian scientists did not have such innovative products. Why? Because as we mentioned earlier, funding of research institutes remained very pure for a long time. Research grants were dolled out, but practically not enough funding for serious preclinical-stage research. There are very few precedents. Russian scientists also did not have modern equipment such a sequencers. They had a lot of ideas and theoretical research, a lot of small but high-quality experiments, but not as a system. However, it often appeared that interesting scientific results that make scientists proud were neither useful nor interesting as potential pharmaceutical products. And time was needed to move them to the stage of marketing. Because of the pure technological basis and lack of practical experience in high-tech manufacturing, development of a new drug takes a lot of time. There is limited experience of successful collaboration between scientists and industry; however, a stable working relationship does not exist. Let's repeat: the main idea in the Strategy is the active innovative development of the Russian pharmaceutical industry, i.e. capturing a the substantial share of the innovative drugs market, and developing production of common generic drugs. Supporting and developing the production of Russian generic drugs is a simple and technologically understandable task. It is a question of political will and quality of management. Production of generic drugs is not complicated; it is very understandable from the point of view of economic processes, technology, and pharmaceutical development. There will be, obviously, fierce competition with India and China, but we can fit into this economical model of existence and develop it. What's more, there are examples when our generic-producing companies had good economical achievements. Yes, they obviously do not make a lot of profits, but $15 \%$ profitability in high-tech production is better than no profitability at all or factories with very old equipment and poorly qualified workers. Developing an innovative way for bio-pharmacy in Russia is possible, because there are a lot of scientific teams in our country that can compete with foreign teams. The main problem is that coordination between drugs manufacturers and scientific research teams is extremely weak, and without such coordination, some areas of scientific research are withering. 